\title{
Big Data Application in Asset Appraisal Using Market Method*
}

\author{
Jinyu Tian, Meijin Xin \\ North China Electric Power University, Baoding, China
}

\begin{abstract}
The big data era is coming, which influences the life of human beings in every aspect, such as working, studying, shopping and so on. The data could be uploaded and recorded by the digital devices like smart-phone and pad. The volume of data could provide useful information to help learn the habit of human beings and improve the efficiency of work. The domain of asset appraisal could make full use of big data to collect and sort information involving the appraised asset and market. On the one hand, market method of asset appraisal needs a plenty of information of reference substance and industry development. On the other hand, big data with the trait of volume and velocity could be utilized to collect information. The paper reveals that taking advantage of big data application in asset appraisal using market method is an evolutionary process in which the gradual understanding of the potential of big data plays a crucial role.
\end{abstract}

Keywords: big data, asset appraisal, market method

\section{Introduction}

\section{Background of Big Data}

Big data is a popular concept for internet people and it attracts more and more attention for the value it owns. The American government issued Big Data Research and Development Initiative on March 29, 2012, which gives the signal to the world that big data to some degree could change the world.

Under the background of supply-side structural reform, Chinese appraisers and the industry of appraising must follow the policy and catch up with the opportunity of big data to improve the capability of appraising. The appraising could serve as an important role in the field of tertiary industry to heed the rallying call of supply-side structural reform to improve the value of the industry.

The burgeoning use of the Internet generates amount of data from individuals and organizations including structured (such as itineraries or transaction reports), semi-structured, and unstructured data (such as text and video). The volume of data rises day by day at the speed of exponential growth, which could deliver some valuable information to companies and government by analyzing the objective law hiding in pictures, words, videos, etc.. Researchers and business men focus their attention on the amount data, namely big data, to arm themselves with the weapon to track social law and make right decisions. It was estimated that at some point between 2008 and 2009, the quantity of connected devices surpassed the number of human beings (Evans, 2011) and Gartner (2014) forecasted that by 2020, there will be 26 billion devices on earth, more than three per living person. As speculated and calculated by Wikibon Ltd., the global output of big data could be up to $\$ 28.1$ billion by 2016 with year-on-year growth of 22\% (Prospective Research Institute, 2017).

\footnotetext{
* Acknowledgement: This paper was supported by 2016 Hebei Province Social Science Fund, No. HB16LJ011. Jinyu Tian, Vice Professor, School of Economics and Management, North China Electric Power University.

Meijin Xin, Postgraduate Student, School of Economics and Management, North China Electric Power University. Email: 191830441@qq.com.
} 
As a new and valuable thing, researchers and organizations have a strong willing to define or describe the big data. The research papers concerned with big data always involve the letter of V, for instance, McAfee and Brynjolfsson (2012) explained big data with Volume, Velocity and Variety. Moving to 2015, Gandomi and Haider (2015) gave more details of big data with other Vs, respectively Value, Variability and Veracity.

De Mauro, Greco, and Grimaldi (2016) came up with the view that validity is an important characteristic of big data, too. The Volume could be described by the unit of quantity of data from the Internet - P as a starting point equals 1024T, then a bigger one E (1024P) and next stage Z (1 1024E).

Velocity could be explained by the speed of data generating and data increasing, the numerous proliferation of personal devices connected to the Internet and equipped with digital sensors (such as cameras, audio recorders and GPS locators), considering the function of Wechat and Facebook in life, which could be delivered at once without any consciousness. Such sensors make digitisation possible, while network connection enables data to be collected, transformed, and ultimately, organized as information.

The sensors also make big data variety, which build and yield a quantity of unstructured data on social internet.

Value, the character we need to improve our life and work, is low actually for the volume is raw without manipulating and it has noise. The staff need to process big data in order to find out the actual value in it as the demand of object and take advantage of it to make decisions.

Noise mentioned above is related to the nature of Veracity. Some data collected are not true, repetitive or cannot match with demand. Some unstructured data could not be used.

Validity is the requirement of the information provided by big data. The Veracity and Validity could contribute to valuable big data. Variability means that the nature of data has finished the process from quantitative change to qualitative change.

\section{Big Data Processing}

After analyzing the literatures concerning big data about 1,400 records, De Mauro et al. (2016) gave a definition of big data: "It is the information asset characterised by such a high volume, velocity and variety to require specific technology and analytical methods for its transformation into value”. They came up with four themes of the big data: information, technology, methods and impact. Indeed, according to Microsoft, big data describes a process in which "serious computing power" is applied to "seriously massive and often highly complex sets of information". The description of big data is always connected with data processing. Janssen, van der Voort, and Wahyudi (2017) identified four departments which should be involved in the process of big data, consisting of collected, prepared, analyzed and made decisions.

Processing big data means that big data need to be analyzed (Big Data Analytics, BDA), which are needed to create value of the data. Without BDA, the amount of data could only be rubbish forgetting in repository, which means nothing to the world. The ability of organizations to process and manipulate big data could influence the outcome of analysis and the further work in need of the information from big data. Understanding the context of the data and the involving problems could be much more helpful in dealing with big data and mining the most valuable information. Some researchers identify the big data process as chains. A big data chain begins with collecting the data from the sources and ends when data-based decisions are taken. In fact, there are many data sources, variations in flows and decisions. In such a chain, there are many efforts to increase the quantity and quality of published data over time. 
How to process big data? Big data literature relates to the specific technological issues that come hand in hand with the utilization of extensive amounts of data. Dealing with big data at the right speed implies computational and storage requirements that an average IT system might not be able to grant. Big data analytical methods have been singled out by Manyika, Chui, Brown, Bughin, Dobbs, Roxburgh, and Byers (2011) and Chen, Chiang, and Storey (2012). They have obtained a list of the most usual procedures that includes: cluster analysis, genetic algorithms, natural language processing, machine learning, neural networks, predictive modelling, regression models, social network analysis, sentiment analysis, signal processing, and data visualization.

The factors influencing the decision based on big data processing have changed along with time and depend on situation.

Big data could arm assset appraisers to increase efficiency. The technology of big data could combine with market method perfectly which would be explained in detail as follows.

\section{Market Method Armed with Big Data}

Market method is considered as the most acceptable market method, for it is the closest to the requirement of market in the three appraising methods, namely, cost method, market method, income approach, respectively. Market method of asset appraisal has prerequisites. First, there are reference substances in the market for the evaluation asset. Second, the transaction of reference substances should be under the condition of the open market. Last, the factors influencing prices are certain and quantifiable. The prerequisites make market method difficult to practice sometimes. Big data could help solve the problems.

Market method needs relevant reference substances, which means that a big and accurate database could be useful. The resources of database could come from the department of statistics, internet, stock market, some exchanges like futures exchange, etc. Actually, the government has already established big data database, such as data.gov in America. Thus, as for asset appraisal, the database should be managed in order under the standard and requirement of asset appraisal, such as dividing the data into distinguished departments, real estate, machines, finance, etc. The step is very important, which decides that the database is established for appraisers and has particular industry traits. Then, there could be more classifications, such as the preference of customers, time, governments or non-government, composite and entire asset or single asset, etc. The database must follow the actual transactions and the development of economy. Besides, the data providing information should have a warrant of accuracy, which could lead to the final results of appraisal.

The database should be established by combining with other organizations to collect data rather than collecting by the single industry. The database should integrate discrepancies that from different industries. When the database could cross borders among different industries, the reference substances could be found easier and more information could be used to ensure parameter. Collaborating and cross-border cooperation are the most important elements to build database. Coordinating all beneficiary subjects to collect information to warrant the appraisal result is difficult. The point of appraisal industry involving in big data is coordinating with government and internet companies to acquire data for they have absolute advantage to collect information.

After building the database, the data should be processed elaborately with advanced technology. Some researchers said that big data analysis has replaced the traditional algorithm and logical connections (Janssen et al., 2017), such as simple induction and deduction methods, which could be utilized difficultly in mining information deeply hiding in the disorder and huge volume of big data. It is reasonable to presume that the consequence of big data application in asset appraisal could modify and improve the methods and results of asset appraisal. 
Big data could be dealt by computer technology along with the model of statistics that could separate and spot effective information concerning asset appraisal. The artificial intelligence, machine learning and neural network cloud computing and other frontier technologies could be armed to handle with data. The huge volume of data contains mass information could be made full use of by systematic and scientific methods to value asset and speculate trends in the future.

\section{Reference Substances}

Big data is actual amount of data from market and transactions, which could guarantee thtat the reference substance is from open market. If the appraisers could find reference substances from database or the advanced system could single out and match the data with object assets, the reference substances will be certain easily. Furthermore, the analysis of processing data could figure out the factors influencing prices. Moreover, the big data could skip the step of choosing reference substances to some extent. The amount of data from market could be the reference substance only if it could match with the object. There exists some noise in the market data, but big data techniques offer enough flexibility to cope with such intrinsically heterogeneous information assets. The computer system could adjust related factors, such as time, function, and appearance to choose the suitable correction factors and then give the appraising value.

Big data could improve the level of representativeness of reference substances, appraisers could choose every aspect and trait of objects to match a transaction involved in similar object owning the same aspects of trait, and then appraisers could find the value of every aspect of the objects in the market. Then, appraisers could integrate all information of all traits to give the results of appraisal.

\section{Examination and Verification}

Big data technique could examine and verify the validity of reference substances by communicating record such as qq and email. All the data could be written down and saved as data in the system. Furthermore, the data could serve as testimony, easily finding and calling in structured system, to prove that the reference and appraisal process is reasonable and regulated.

\section{Adjusting Parameter}

Big data could be taken advantage by market method to eliminate subjectivity of appraisers such as experience and judgment. Big data with scientific analysis and processing precisely by computer, for instance, cloud computing, could offer appraisers more accurate parameters and correction factors. The larger volume of data, the more information of market transaction price consisted, which means that the number of samples is much more than the number of samples collected by hand from 3 to 5 at most of the time. Further, the increasing number of samples could turn into more accurate parameters. If combining big data with market method of asset appraisal, the market method would be much more scientific on account of the support of amount of objective data from efficient market. Currently, the appraisers would choose samples by hand and experience of long-term operation and adjusting parameters by their own experience. The whole process practiced by appraisers probably hides a quantity of subjective factors of appraisers themselves, which are difficult to eliminate as human beings. Compared to human, computer and arithmetic could excavate more objective information from big data. 
There are some kinds of asset which could be discussed in detail involving appraising them by market method with big data. Real estate is suitable to be evaluated by market method, which already has software or computer system to value the asset involving big data. Intangible asset itself is better to be appraised by earning method than market method. Nonetheless, the big data and advanced processing data technology could deal with the problem such as shortage of reference substances, of intangible asset involving market method. Then, intangible assets could be handled by companies to make full use of market method improved by big data. Machines, always appraising by cost method traditionally, could also receive new market method to give market acceptable prices.

The value of big data mixed up with market method also originates from the ability to appraise at any time along with the frequencies of trade without few days waiting. The speed and promptness are the requirements of market and guests, which could influence important decision-making.

\section{Conclusion}

Value from big data could be extended to the field of asset appraisal by supporting market method with abundant and structured data in detail. The powerful and structured database could come from government and internet companies which could provide appraisal information to appraisers at a reasonable price. The technology of big data is new to appraisal industry in the requirement of the professional in appraisal field studying and mastering it to catch up with the era. The process of data could lead to different results for the information acquired is different. The ability of appraisers to use big data technology is significant.

The main limitation of this study relates to the absent specific case study within the field of asset appraisal. Finding a suitable case study was found to be challenging, however, the case study revealed experiences that have not been found in the literature yet. Further research can focus on cases from different domains of asset appraisal and on generalizing the factors influencing the development of big data in asset appraisal.

\section{References}

Chen, H., Chiang, R. H. L., \& Storey, V. C. (2012). Business intelligence and analytics: From big data to big impact. MIS Quarterly, 36(4), 1165-1188.

De Mauro, A., Greco, M., \& Grimaldi, M. (2016). A formal definition of big data based on its essential features. Library Review, 65(3), 122-135.

Evans, D. (2011). The internet of things - How the next evolution of the Internet is changing everything. San Jose, CA: Cisco Systems, Inc.

Gandomi, A., \& Haider, M. (2015). Beyond the hype: Big data concepts, methods, and analytics. International Journal of Information Management, 35(2), 137-144.

Gartner. (2014). Gartner says the internet of things will transform the data center. Retrieved from http://www.gartner.com/newsroom/id/2684616

Janssen, M., van der Voort, H., \& Wahyudi, A. (2017). Factors influencing big data decision-making quality. Journal of Business Research, 70, 338-345.

Manyika, J., Chui, M., Brown, B., Bughin, J., Dobbs, R., Roxburgh, C., \& Byers, A. H. (2011). Big data: The next frontier for innovation, competition, and productivity. McKinsey Global Institute, New York, NY.

McAfee, A., \& Brynjolfsson, E. (2012). Big data: The management revolution. Harvard Business Review, 90(10), 61-67.

Prospective Research Institute. (2017). Report of prospects and investment strategy planning on China big data industry (2018-2023). Beijing. 